\title{
Bis(1,3-dinitratoprop-2-yl) Nitramine, a New Sensitive Explosive Combining a Nitrate Ester with a Nitramine
}

\begin{tabular}{|r|l|}
\hline Journal: & Zeitschrift für Anorganische und Allgemeine Chemie \\
\hline Manuscript ID: & zaac. 201000229 \\
\hline Wiley - Manuscript type: & Article \\
\hline Date Submitted by the \\
Author: & O2-Jun-2010 \\
\hline Complete List of Authors: & $\begin{array}{l}\text { Klapoetke, Thomas } \\
\text { Krumm, Burkhard; LMU, Cheistry } \\
\text { Steemann, Xaver; LMU, Cheistry }\end{array}$ \\
\hline Keywords: & Explosives, Nitramines, Nitrate ester \\
\hline
\end{tabular}

\section{(s) ScholaroNE \\ Manuscript Central}




\title{
Bis(1,3-dinitratoprop-2-yl) Nitramine, a New Sensitive Explosive Combining a Nitrate Ester with a Nitramine
}

\author{
Thomas M. Klapötke, ${ }^{*[a]}$ Burkhard Krumm, ${ }^{[\mathrm{a}]}$ F. Xaver Steemann, ${ }^{[\mathrm{a}]}$ and Klaus-Daniel Umland ${ }^{[\mathrm{a}]}$ \\ In memory of Herbert Schumann, an outstanding chemist and great friend
}

Keywords: Explosives; Nitramines; Nitrate ester

\begin{abstract}
Nitro functionalized compounds comprise a large substance class and are the most popular explosive materials.

interest. This work is concerned with the synthesis and Recent research furnished a solid energetic nitrate ester of potential characterization of novel aliphatic nitramine compounds with similar features.
\end{abstract}

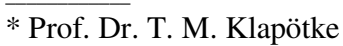

Fax: +49(0)89-2180-77492

E-mail tmk@cup.uni-muenchen.de

[a] Department of Chemistry,

Energetic Materials Research,

Ludwig-Maximilian University Munich (LMU),

Butenandtstrasse 5-13 (D),

81377 Munich, Germany

\section{Introduction}

Ever since the discovery of nitroglycerine (1 in Scheme 1) by Ascanio Sobrero in 1846 [1], chemists have investigated nitrated and nitro functionalized compounds for the use as energetic substances. These endeavours furnished e.g. pentaerythritol tetranitrate (PETN, 2 in Scheme 1), a very powerful aliphatic nitrato compound, which is not as easy to detonate by means of shock or friction as is nitroglycerine. Recent research led to the synthesis of 2,3-bis(hydroxymethyl)-2,3-dinitrobutane-1,4-diol tetranitrate (NEST-1, 3 in
Whereas nitroglycerine becomes handy only when mixed with desensitizing agents such as cellite in the composition dynamite, other aliphatic nitrates, e.g. PETN and NEST-1, display sensitivities against mechanical stress that allow safe use of the pure compounds.

With remarkable structural similarity to nitroglycerine, the nitramine $\mathbf{4}$ is reported to be explosive as well. Literature about this compound is rather scarce, despite the huge amount of data available on ethyl analogon $\mathbf{5}$ and on other nitramine compounds [3].

In this paper, the new nitro-aliphatic nitramine bis(1,3dinitratoprop-2-yl) nitramine (6 in Scheme 1) is presented as the most recent outcome of the quest for highly energetic compounds of reduced sensitivity and $\mathbf{4}$ is investigated more closely.

Scheme 1) [2]. 
<smiles>O=[N+]([O-])OCC(CO[N+](=O)[O-])O[N+](=O)[O-]</smiles>

1
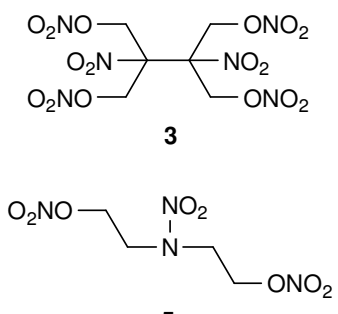

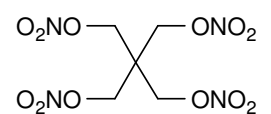

2

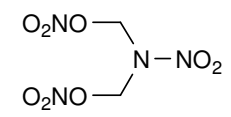

4

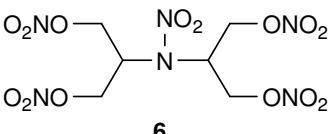

Scheme 1. Investigated nitro compounds.

\section{Results and Discussion}

The synthesis of bis(1,3-dinitratoprop-2-yl) nitramine (6) was performed via nitration of the hydroxy-amine bis-(1,3dihydroxyprop-2-yl)-amine, which in turn can be obtained from 1,3-dihydroxyacetone as reported [4]. Bis(nitratomethyl)-nitramine (4) was obtained from the reaction of bis-(chloromethyl)-nitramine [5] with silver nitrate. Compound 4 decomposes upon longer exposure to humidity.

The respond of the compounds to stress was tested in form of impact by a drop hammer and friction imposed by a friction tester apparatus. The test procedures detailed in EC 440/2008 [6] were used for the determination of sensitivities. In case of $\mathbf{1}, \mathbf{3}$ and $\mathbf{5}$, the literature values $[1,2,7]$ are given in Table 1.

Table 1. Mechanic sensitivities.

$\begin{array}{lll}\text { Compd. } & \boldsymbol{E}_{\mathbf{d r}} / \mathbf{J} & \boldsymbol{F}_{\mathbf{r}} / \mathbf{N} \\ \mathbf{1} & 0.2 & 353 \\ \mathbf{2} & 3 & 60 \\ \mathbf{3} & 2.7 & 74.5 \\ \mathbf{4} & 2 & 56 \\ \mathbf{5} & 6 & \text { n.d. } \\ \mathbf{6} & 0.5 & 353\end{array}$

Formal substitution of the central $\mathrm{HCONO}_{2}$ moiety in $\mathbf{1}$ with the nitramino moiety $\mathrm{NNO}_{2}$ leads to the nitramine 4 . Its impact sensitivity was found to be significantly lower.
Possibly, the sensitizing interaction of adjacent $\mathrm{H}_{2} \mathrm{CONO}_{2}$ moieties is stronger than the interaction between a $\mathrm{H}_{2} \mathrm{CONO}_{2}$ moiety and a neighboring nitramino functionality. It cannot be excluded that a sensitizing interaction between both terminal nitrato carbon centers in $\mathbf{1}$ is blocked by the nitramino "insert" in 4 . If the carbon centered nitrato groups are even farther from the nitramine center, and thus from each other as well, apart, as in the nitramine dioxyethylnitramine dinitrate (DINA, 5), a further decrease in impact sensitivity is observed in accordance with the expectation.

Compounds 3 and $\mathbf{6}$ resemble more complex molecules. Compound $\mathbf{3}$ can be seen as dimer of nitroglycerine (1) derived by C-C linkage. The sensitivities of $\mathbf{3}$ are comparable to PETN (2). If the central nitrato functionality in 1 was omitted and a nitramine-linked dimer formed, compound 6 would formally be obtained. As Table 1 indicates, compound $\mathbf{6}$ is only slightly less sensitive towards impact as 1. Because the introduction of a nitramine moiety into an energetic alkylnitrato compound (e.g. 4 and 5) should result in a significant decrease in sensitivity, the steric effects of the linkage of two 1,3-dinitratoprop-2-yl moieties seem to almost compensate the de-sensitizing effect. For compound 3, where the linkage is a simple C-C single bond, this effect obviously is stronger as for the nitramine-linked dimer 6. From this, substitution of nitrato functionalities by $\mathrm{C}$-linked nitro groups seem to de-sensitize even more than does the introduction of a nitramine functionality.

The friction sensitivity should be mostly influenced by the mechanical properties of the substance such as its hardness. Therefore, much more force would be necessary to 
successfully initiate decomposition of a soft energetic material. This explains nicely the high friction values for the oils 1 and $\mathbf{6}$ and lower values for the other (solid) compounds. Friction sensitivities of $\mathbf{2}$ and $\mathbf{4}$ are comparable, and both compounds are found roughly by $15 \mathrm{~N}$ more sensitive towards friction than 3. However, the discrepancies between the friction sensitivities of compounds $\mathbf{2}, \mathbf{3}$ and $\mathbf{4}$ cannot be explained satisfactorily by a look at the molecular structures. For the liquid DINA (5) no friction value is reported in literature, the measurement of friction sensitivities of liquids is rarely performed.

The melting point of 6 was determined to $23-25{ }^{\circ} \mathrm{C}$ and under cool conditions, the compound can be obtained as solid substance. Crystals of $\mathbf{6}$ were obtained by slow diffusion of n-hexane into a saturated solution of $\mathbf{6}$ in dichloromethane. The crystal structure of the new nitratoalkyl nitramine $\mathbf{6}$ was solved in the orthorhombic space group $P 2_{1} 2_{1} 2_{1}$ with four formula units per unit cell. The asymmetric unit represents one formula moiety (Fig. 1).

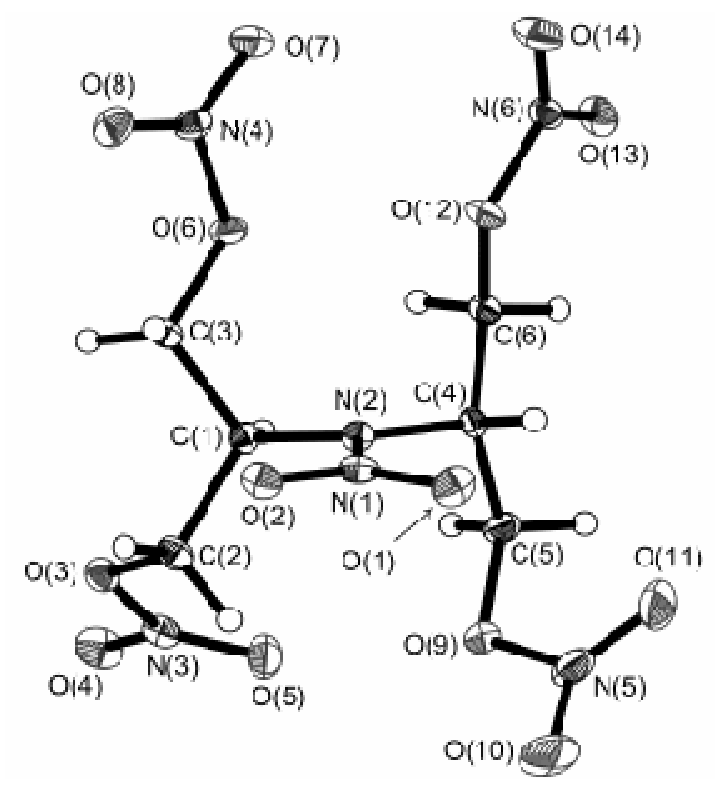

Figure 1. Asymmetric unit of 6. Crystal data: $\mathrm{C}_{6} \mathrm{H}_{10} \mathrm{~N}_{6} \mathrm{O}_{14}, M=$ 390.18, $a=6.1227(2) \AA, b=10.4051$ (2) $\AA$, $c=22.3943(2) \AA$, $U=1426.67(6) \AA^{3}, T=100 \mathrm{~K}, 8282$ reflections measured, 2410 unique $\left(R_{\text {int }}=0.031\right)$ which were used in calculations. The final $w R\left(F_{2}\right)$ was 0.067 (all data).
Because the present study is focussed on nitrate ester compounds, energetic properties have to be discussed. In order to predict energy release as well as detonation characteristics (pressure, temperature and velocity), the enthalpies of formation and densities can be used in conjunction with the EXPLO5 thermodynamic code [8].

A simple estimation of the enthalpies of formation can be done by increment calculations using average increment enthalpy values from the literature [9]. Intramolecular interactions between nitro or nitrato functionalities can be taken into account. Table 2 lists the calculation results as well as values obtained by bomb calorimetric measurements resp. quantum chemical calculations (CBS-4M) [10].

Table 2. Enthalpies of formation (in $\mathrm{kJ} / \mathrm{mol}$ ).

$\begin{array}{ccc} & \begin{array}{c}\text { Calculated (group } \\ \text { additivity) }\end{array} & \text { Measured / Calculated }^{\mathbf{a}} \\ \mathbf{1} & -371 & -371[7] \\ \mathbf{2} & -532 & -593[7] \\ \mathbf{3} & -674 & -469(\mathrm{CBS}-4 \mathrm{M}) \\ \mathbf{4} & -102 & -108 \\ \mathbf{5} & -279 & -276[7] \\ \mathbf{6} & -379 & -1055 /-1068(\mathrm{CBS}-4 \mathrm{M})\end{array}$

a) values from bomb calorimetric measurements unless noted otherwise

For substances 1, 2, 4, and 5 good agreement between calculated and measured enthalpies is observed. For the more heavily branched nitrato alkyls $\mathbf{3}$ and $\mathbf{6}$, measurement and increment calculation widely disagree. Obviously, the intramolecular interactions in these molecules are not adequately represented by the increment values from literature. For compound 6, calorimetric measurements confirm the CBS-4M result.

Using the measured and reported enthalpies of formation, the EXPLO5 computer code [8] calculates the detonation parameters of the compound at the $\mathbf{C J}$ point with the aid of the steady-state detonation model. A modified 
Becker-Kistiakowski-Wilson equation of state is used to model the system. The CJ point is found from the Hugoniot curve of the system by its first derivative [11]. The resulting heats of detonation $\left(Q_{\mathrm{v}}\right)$, detonation temperatures $(T)$, pressures $(p)$ and velocities $(D)$ are shown in Table 3, as are the oxygen balances $(\Omega)$.

Table 3. Detonation parameters.

$\begin{array}{cccccccc} & \begin{array}{c}\boldsymbol{\rho} \\ \end{array} & \boldsymbol{\Omega}(\boldsymbol{\%}) & \begin{array}{c}\boldsymbol{Q}_{\mathbf{v}} \\ \left(\mathbf{g} / \mathbf{c m}^{\mathbf{3}}\right)\end{array} & \boldsymbol{T}(\mathbf{K}) & \boldsymbol{p} & \boldsymbol{D} & \boldsymbol{D}_{\text {meas. }}(\mathbf{m} / \mathbf{s})^{\mathbf{b}} \\ \mathbf{1} & 1.591 & +3.52 & -6037 & 4629 & 236 & 7752 & 7600(1.59)[1] \\ \mathbf{2} & 1.760 & -10.12 & -5923 & 4423 & 318 & 8652 & 8400(1.7)[1] \\ \mathbf{3} & 1.917 & 0 & -6569 & 4814 & 367 & 9023^{\mathrm{a}} & 9100[2] \\ \mathbf{4} & 1.860 & +15.09 & -5426 & 4303 & 315 & 8525 & \\ \mathbf{5} & 1.488 & -21.65 & -5473 & 4057 & 217 & 7645 & 7580(1.47) \\ & & & & & & & {[1]} \\ \mathbf{6} & 1.817 & -12.30 & -4683 & 3650 & 285 & 8245^{\mathrm{a}} & \end{array}$

a) EXPLO5 values based on CBS-4M results; b) For 3 the reported value was calculated theoretically

With high detonation velocity and pressure, the nitrate ester 3 turns out to be the most promising energetic substance, comparable to PETN (2), the nitrato nitramines 4 and KBX (6) display slightly lower detonation values. The lowest values are observed for nitroglycerine (1) and DINA (5), both in the same range.

\section{Conclusions}

The new nitramine $\mathbf{6}$ might have some advantages in comparison to NEST-1 (3) and the well-established PETN (2), e.g. its very low friction sensitivity, a low melting point and a decomposition temperature of $166^{\circ} \mathrm{C}$ (2: ca. $185^{\circ} \mathrm{C}$ [1], 3: $\left.141^{\circ} \mathrm{C}[2]\right)$. Unfortunately, the impact sensitivity of $\mathbf{6}$ is only slightly lower than for nitroglycerine (1), therefore only applications of $\mathbf{6}$ in desensitized mixtures seem reasonable.

\section{Experimental Section}

Synthesis of bis(1,3-dinitratoprop-2-yl) nitramine (6, KBX)

Nitric acid $(100 \%, 1.8 \mathrm{~mL}, 41 \mathrm{mmol})$ was cooled to $10{ }^{\circ} \mathrm{C}$ and dissolved in glacial acetic acid $(4.4 \mathrm{~mL}, 46 \mathrm{mmol})$. Upon slow addition of bis(1,3-dihydroxyprop-2-yl) amine (0.96 g, $5.8 \mathrm{mmol})$ in acetic acid $(2.3 \mathrm{~mL}, 41 \mathrm{mmol})$, the ice bath was removed and the solution stirred for 72 hours at ambient temperature.

Water $(25 \mathrm{~mL})$ was added and the solution extracted with dichloromethane $(8 \times 25 \mathrm{~mL})$. Aqueous and organic layers were saturated with sodium carbonate and the aqueous layer was again extracted with dichloromethane $(4 \times 25 \mathrm{~mL})$. The united organic layers were washed with water $(25 \mathrm{~mL})$, dried over magnesium sulfate and evaporated. Column chromatography (dichloromethane, silica gel) furnished $1.6 \mathrm{~g}(72 \%) \mathrm{KBX}(6)$ as pale yellow oil. Single crystals were obtained from a saturated solution in dichloromethane by slow diffusion into $n$-hexane.

6: ${ }^{1} \mathbf{H}$ NMR $\left(\mathrm{RT}, \mathrm{CDCl}_{3}\right): \delta=5.52(\mathrm{~m}, 1 \mathrm{H} ; \mathrm{CH}), 4.82(\mathrm{~m}, 2 \mathrm{H}$; $\mathrm{CH} \underline{\mathrm{H}}), 4.66$ (m, $2 \mathrm{H} ; \mathrm{C} \underline{\mathrm{H}})$ ppm. ${ }^{13} \mathrm{C}$ NMR $\left(\mathrm{RT}, \mathrm{CDCl}_{3}\right): \delta=74.7$ $(\mathrm{CH}), 68.0\left(\mathrm{CH}_{2}\right) \mathrm{ppm} .{ }^{15} \mathrm{~N}$ NMR $\left(\mathrm{RT}, \mathrm{CDCl}_{3}\right): \delta=-49.1\left(\mathrm{NO}_{2}\right)$, $-49.2\left(\mathrm{ONO}_{2}\right)$ ppm. IR: $v\left(\mathrm{~cm}^{-1}\right)=3025 \mathrm{w}, 2965 \mathrm{w}, 2914 \mathrm{w}, 2852$ w, 1631 vs, 1526 w, 1292 m, 1267 vs, 1086 w, 1015 m, 896 w, 824 s, 751 m, 699 w, 625 w. $\operatorname{Raman}(400 \mathrm{~mW}): v\left(\mathrm{~cm}^{-1}\right)=2986$ (100), 2774 (13), 1647 (18), 1457 (17), 1292 (56), 857 (41), 555 (17). Elemental analysis: Calcd. $\left(\mathrm{C}_{6} \mathrm{H}_{10} \mathrm{~N}_{6} \mathrm{O}_{14}\right)$, found (\%): C 18.5 , 18.7; H 2.6, 2.7; N 21.5, 20.7. DSC (crystals): mp: $\sim 25{ }^{\circ} \mathrm{C}$, decomposition $>165{ }^{\circ} \mathrm{C} . \quad \boldsymbol{K}_{\mathbf{o w}}=172.4 . \quad \boldsymbol{E}_{\mathrm{dr}}<0.5 \mathrm{~J}$ (liquid). $\quad \boldsymbol{F}_{\mathrm{r}}<$ $353 \mathrm{~N}$.

\section{Structure Determination}

The single crystal X-ray diffraction data of $\mathbf{6}$ were collected using an Oxford Xcalibur3 diffractometer with a Spellman generator (voltage $50 \mathrm{kV}$, current $40 \mathrm{~mA}$ ) and a KappaCCD detector. The data collection was undertaken using the CrysAlis CCD software 
[12] and the data reduction was performed with the CrysAlis Red software [13]. The structure was solved with Sir-92 [14] and refined with Shelxl-97 [15] implemented in the program package WinGX [16] and finally checked using Platon [17]. Selected data and parameters from the X-ray data collection and refinement are given in Table X. The crystallographic informations file (cif) on 6 has been deposited with the Cambridge Crystallographic Data Centre under the depository number CCDC-775656. Copies of the data can be obtained free of charge on application to The Director, CCDC, 12 Union Road, Cambridge CB2 1EZ, UK (Fax: int. code +(1223)336-033; e-mail for inquiry: fileserv@ccdc.cam.ac.uk; email for deposition: $\underline{\operatorname{deposit} @ \text { ccdc.cam.ac.uk). }}$

Table 4. Crystallographic data of 6.

\begin{tabular}{ll}
\hline formula & $\mathrm{C}_{6} \mathrm{H}_{10} \mathrm{~N}_{6} \mathrm{O}_{14}$ \\
molecular weight / g/mol & 390.18 \\
temperature / K & 100 \\
crystal dimensions / mm & $0.11 \times 0.15 \times 0.29$ \\
crystal system & orthorhombic \\
space group & $P 2_{1} 2_{1} 2_{1}$ \\
$a / \AA$ & $6.1227(2)$ \\
$b / \AA$ & $10.4051(2)$ \\
$c / \AA$ & $22.3943(2)$ \\
$V / \AA^{3}$ & $1426.67(6)$ \\
$Z$ & 4 \\
$\rho_{\text {calc }} /$ g/cm & \\
$\mu / \mathrm{mm}^{-1}$ & 1.8166 \\
$F(000)$ & 0.182 \\
$\theta$ range / & 800 \\
index ranges & $3.79-30.09$ \\
& $-8 \leq h \leq 8$ \\
reflections, measured & $-13 \leq k \leq 14$ \\
reflections, unique & $-19 \leq l \leq 31$ \\
$R 1, w R 2(2 \sigma)$ & 8282 \\
$R 1, w R 2($ all $)$ & $2410\left(R_{\text {int }}=3.1 \%\right)$ \\
data/restraints/parameters & $0.0291 / 0.0590$ \\
$\mathrm{GOOF}$ of $F^{2}$ & $0.0448 / 0.0656$ \\
residual densities / e/ $\AA^{3}$ & $2410 / 0 / 235$ \\
\hline & 0.984 \\
& $0.229 /-0.240$ \\
\hline
\end{tabular}

\section{Acknowledgment}

The authors are indebted and wish to thank Ms. C. Evangelisti for the CBS-4M calculations, Dr. M. Scherr for the X-Ray structure determination and Mr. S. Huber for the bomb calorimetric measurements. Financial support of this work by the Ludwig-Maximilian University of Munich (LMU), the U.S. Army Research Laboratory (ARL), the Armament Research, Development and Engineering Center (ARDEC), the Strategic Environmental Research and Development Program (SERDP) and the Office of Naval Research (ONR Global, title: "Synthesis and Characterization of New High Energy Dense Oxidizers (HEDO) - NICOP Effort") under contract nos. W911NF-092-0018 (ARL), W911NF-09-1-0120 (ARDEC),

W011NF-09-1-0056 (ARDEC) and 10 WPSEED01-002 / WP-1765 (SERDP) is gratefully acknowledged.

\section{References}

[1] (a) B. T. Fedoroff, Encyclopedia of Explosives and Related Items, Picantinny Arsenal, New Jersey, USA, 1960-1983;

(b) T. M. Klapötke, Chemie der hochenergetischen Materialien, Walter de Gruyter, Berlin, 2010.

[2] D. E. Chavez, M. A. Hiskey, D. L. Naud, D. Parrish, Angew. Chem. Int. Ed. 2008, 47, 8307-8309.

[3] Y.-H. Joo, J. M. Shreeve, Chem. Commun. 2010, 46, 142-144.

[4] (a) D. A. Scott, T. M. Kruelle, M. Finn, R. J. Nash, A. L. Winters, N. Asano, T. D. Butters, G. W. Fleet, Tetrahedron Lett. 1999, 40, 75817584

(b) J.E. Flanagan, M.B. Frankel, Rockwell International Corp. USA, US 4085 123, 1978.

[5] J. E. Flanagan, M. B. Frankel, US Pat., 4085 123, 1978.

[6] Commission Regulation (EC) No 761/2009 of 23 July 2009 amending, for the purpose of its adaptation to technical progress, Regulation (EC) No 440/2008 laying down test methods pursuant to Regulation (EC) No 1907/2006 of the European Parliament and of the Council on the Registration, Evaluation, Authorisation and Restriction of Chemicals (REACH).

[7] J. A. Köhler, A. Homburg, R. Meyer, in Expolsivstoffe, Wiley-VCH, Weinheim, 6th edn., 2008.

[8] M. Suceska, EXPLO 5 Program, Zagreb, 2005. 
[9] E. V. Sagadeev, A. A. Gimadeev, V. P. Barabanov, Theor. Found. Chem. Eng. 2009, 43, 108-118; A. N. Kizin, P. L. Dvorkin, G. L. Ryzhova, Yu. A. Lebedev, Izv. Akad. Nauk. SSSR, Ser. Khim. 1986, $372-375$.

[10] J. A. Montgomery, M. J. Frisch, J. W. Ochterski, G. A. Petersson, J. Chem. Phys. 2000, 112, 6532-6542; J. W. Ochterski, G. A. Petersson, J. A. Montgomery, J. Chem. Phys. 1996, 104, 2598-2619.

[11] M. Suceska, Propellants, Explos., Pyrotechn, 1991, 16, 197-202.

[12] CrysAlis CCD, Oxford Diffraction Ltd., Version 1.171.27p5 beta (release 01-04-2005 CrysAlis171 .NET).

[13] CrysAlis RED, Oxford Diffraction Ltd., Version 1.171.27p5 beta (release 01-04-2005 CrysAlis171 .NET).

[14] A. Altomare, G. Cascarano, C. Giacovazzo, A. Guagliardi, Appl. Cryst. 1993, 26, 343.

[15] Sheldrick, G. M. Shelxl-97, Program for the Refinement of Crystal Structures, University of Göttingen, Germany, 1994.

[16] L. Farrugia, L. J. J. Appl. Cryst. 1999, 32, 837-838.

[17] A. L. Spek, Platon, A Multipurpose Crystallographic Tool, Utrecht University, Utrecht, The Netherlands, 1999.

Received: ((will be filled in by the editorial staff)) Published online: ((will be filled in by the editorial staff 
5

6
7

8

9

10

11

12

13

14

15

16

17

18

19

20

(1)

23

24

25

26

27

29

30

31

32

33

34

35

36

37

38

39

40

41

42

43

44

45

46

47

48

49

50

51

52

53

54

55

56

57

58

59 